\title{
Endometriosis as a Cause of Primary Infertility in Western Regions of Saudi Arabia
}

\author{
Khalid Khadawardi \\ Umm Al-Qura University, Makkah, Saudi Arabia \\ Email:khadawardi@icloud.com
}

How to cite this paper: Khadawardi, K. (2020) Endometriosis as a Cause of Primary Infertility in Western Regions of Saudi Arabia. Open Journal of Obstetrics and Gynecology, 10, 333-340. https://doi.org/10.4236/ojog.2020.1030030

Received: February 2, 2020

Accepted: February 29, 2020

Published: March 3, 2020

Copyright $\odot 2020$ by author(s) and Scientific Research Publishing Inc. This work is licensed under the Creative Commons Attribution International License (CC BY 4.0).

http://creativecommons.org/licenses/by/4.0/

(c) (i) Open Access

\begin{abstract}
Background: Endometriosis is defined by the presence of viable extrauterine endometrial glands and stroma with unclear etiology and pathogenesis. It has been associated with female infertility. Infertility is defined as the failure of sexually active couple, not using contraception to achieve a clinical pregnancy after one year or more of regular sexual intercourse. Infertility is a symptom of endometriosis in up to $50 \%$ of women. Methods: Descriptive cross-sectional study was conducted in Kind Abdulaziz Hospital in Almina, South Jeddah, Saudi Arabia. The total sample obtained was 507 participants. Participants were married Saudi women attending the outpatient or inpatient departments in the hospital. Pre-designed disseminated questionnaire was distributed for data collection, and data were entered and analyzed using the Statistical Package for the Social Science (SPSS Inc. Chicago, IL, USA) version 23. Results: Most (47.9\%) of the studied women aged 31 - 40 years, $41.9 \%$ were obese and $1.2 \%$ were smokers while $42.2 \%$ were passive smokers, and only $3.7 \%$ exercise regularly. Prevalence of infertility was $23.3 \%$ and endometriosis was $10.7 \%$. It was found that there was a significant correlation between endometriosis and infertility $(\mathrm{P}=0.025)$. Conclusion: Although many women with endometriosis get pregnant and deliver healthy infants, endometriosis is highly associated with infertility. More studies are needed to investigate the pathobiology of this condition.
\end{abstract}

\section{Keywords}

Endometrosis, Infertility, Awareness, Complications

\section{Introduction}

Endometriosis is a gynecological enigma since it is difficult to diagnose and treat. Endometriosis is a benign disease in which endometrial-like tissue persists 
outside of the uterus. Pelvic structures are most commonly affected, but endometriosis can involve extrauterine organs as distant as the lung [1]. True prevalence data are not known since most of studies investigate high risk groups and the fact that it is easily overlooked by the primary care physicians. However, it was estimated that it has a global prevalence of $10 \%$ among women during their reproductive years [2]. Not only to affected women, but Endometriosis constitutes a burden and lowers the quality of life of also their families, partners, and the healthcare system [3].

Infertility, by the WHO definition, is the failure of a sexually active couple, not using contraception to achieve a clinical pregnancy after one year or more of regular sexual intercourse [4] [5]. Available data show that at least 50 million couples experience infertility, globally [6]. Even though either of the sexually active couple can cause infertility, the majority of data reported on infertility is conducted among women, and global data on male infertility is insufficient [6].

Many factors have been attributed to the risk of female infertility. Endometriosis had been associated with infertility and recent studies found that infertility affects up to $50 \%$ of females with endometriosis. Some cases are diagnosed with endometriosis during the investigations of infertility [7]. Fecundity among normal conceiving couples is in the range of 0.15 to 0.20 per month, which decreases with age. However, fecundity among women with endometriosis is about 0.02 to 0.1 per month [8] [9]. Endometriosis is also reported to be associated with lower live birth rate [10]. Moreover, women with endometriosis tend to have other endocrine and ovulatory disorders [11].

This study aims to assess the prevalence of endometriosis and infertility and investigate the association between both conditions.

\section{Methods \& Participants}

\subsection{Study Design and Setting}

A cross-sectional study was carried out in Almina, South Jeddah, Saudi Arabia. The study was done in King Abdulaziz Hospital during the period from March to September 2018.

\subsection{Sampling and Data Collection}

The targeted population was all married Saudi women attending the outpatient or inpatient departments in King Abdulaziz Hospital in Almina, South Jeddah, Saudi Arabia. All those agreed to participate were included. The total sample obtained was 507 participants. All participants were Saudi, married and could read and understand the questionnaire.

Pre-designed disseminated questionnaire was distributed for data collection throughout the period (March-September 2018).

Inclusion criteria: participants enrolled in the study were female adults, Saudi, married, and completed correct filling of the form. 
Exclusion criteria: participants who were not willing to participate, who did not understand the questions properly and incorrectly filled the form.

\subsection{Data Collection Tools}

Participants were approached with a self-administered questionnaire to be filled by them with the guidance of the data collectors. A letter that explains the objectives of the study and asks for participants' consent was attached to the questionnaire.

The questionnaire required information about history of endometriosis, as well as infertility. The questionnaire also included questions regarding age, marital period, regularity of menses, smoking, BMI, history of associated conditions, assisted pregnancy, abortion or defects in ovulation.

\subsection{Sample Size}

We expected a high response rate, however, we eliminated all invalid, incomplete responses or any responses that did not match the inclusion criteria with a total of 507 participants.

\subsection{Data Management and Statistical Analysis}

The collected data was entered and analyzed using the Statistical Package for the Social Science (SPSS Inc. Chicago, IL, USA) version 23. Descriptive statistics were performed. Percentages were given for qualitative variables. The determinant factors were determined using the Chi-square test. P-value was considered significant if $\mathrm{P}<0.05$.

\subsection{Ethical Considerations}

The participants were informed that participating is completely voluntary. All the participants were aware that their data will be dealt with confidentially. No names were written in the forms and the data was kept safely.

\section{Results}

Table 1 shows the age group, BMI group, Smoking status, and exercise rates among the studied women. Most (47.9\%) of the studied women aged $31-40$ years, $41.9 \%$ were obese and $1.2 \%$ were smokers while $42.2 \%$ were passive smokers, and only $3.7 \%$ exercise regularly.

Table 2 shows that $30 \%$ of women have regular menstruation, $23.3 \%$ had children, 30.2\% have assisted pregnancy. Almost half (54\%) of studied women had delayed fertility for over 1 year and $38.9 \%$ have history of abortion. Defects of ovulation were reported by $28.8 \%$ of studied women.

Table 3 shows the prevalence of infertility (23.3\%) and endometriosis (10.7\%).

Table 4 illustrates the relationship between infertility and endometriosis. It was found that there was a significant correlation between endometriosis and infertility $(\mathrm{P}=0.025)$. 
Table 1. Age group, BMI group, smoking, passive smoking, in the studied women, Jeddah, $2019(\mathrm{n}=507)$.

\begin{tabular}{|c|c|c|}
\hline Variables & Frequency $(N=507)$ & Percent \\
\hline \multicolumn{3}{|l|}{ Age group } \\
\hline$-\quad<21$ & 1 & 0.2 \\
\hline$-\quad 21-30$ & 157 & 31.0 \\
\hline$-\quad 31-40$ & 243 & 47.9 \\
\hline$->40$ & 106 & 20.9 \\
\hline \multicolumn{3}{|l|}{ BMI group } \\
\hline - Underweight & 2 & 0.4 \\
\hline - Normal & 143 & 28.2 \\
\hline - Overweight & 151 & 29.8 \\
\hline - Obese & 211 & 41.6 \\
\hline \multicolumn{3}{|l|}{ Smoking } \\
\hline$-\quad$ No & 501 & 98.8 \\
\hline - Yes & 6 & 1.2 \\
\hline \multicolumn{3}{|l|}{ Passive smoking } \\
\hline$-\quad$ No & 293 & 57.8 \\
\hline - Yes & 214 & 42.2 \\
\hline \multicolumn{3}{|l|}{ Exercise } \\
\hline$-\quad$ No & 298 & 58.8 \\
\hline - Irregular & 190 & 37.5 \\
\hline - Regular & 19 & 3.7 \\
\hline
\end{tabular}

Table 2. Medical history of participants $(n=507)$.

\begin{tabular}{|c|c|c|}
\hline Variables & Frequency $(\mathrm{N}=507)$ & Percent \\
\hline \multicolumn{3}{|l|}{ Regular menstruation } \\
\hline - Yes & 155 & 30.6 \\
\hline$-\quad$ No & 352 & 69.4 \\
\hline \multicolumn{3}{|l|}{ Do you have children? } \\
\hline - Yes & 389 & 76.7 \\
\hline$-\quad$ No & 118 & 23.3 \\
\hline \multicolumn{3}{|l|}{ Assisted pregnancy } \\
\hline - Yes & 153 & 30.2 \\
\hline$-\quad$ No & 354 & 69.8 \\
\hline \multicolumn{3}{|c|}{ Delayed fertility (over 1 year) } \\
\hline - Yes & 274 & 54.0 \\
\hline$-\quad$ No & 233 & 46.0 \\
\hline \multicolumn{3}{|l|}{ History of abortion } \\
\hline - Yes & 197 & 38.9 \\
\hline$-\quad$ No & 310 & 61.1 \\
\hline \multicolumn{3}{|l|}{ Defect in ovulation } \\
\hline - Yes & 146 & 28.8 \\
\hline$-\quad$ No & 361 & 71.2 \\
\hline
\end{tabular}


Table 3. Prevalence of infertility and endometriosis among participants $(n=507)$.

\begin{tabular}{lcc}
\hline \multicolumn{1}{c}{ Variables } & Frequency $(\mathrm{N}=507)$ & Percent \\
\hline $\begin{array}{l}\text { Diagnosis with primary or } \\
\text { secondary infertility }\end{array}$ & 118 & \\
$\quad-\quad$ Yes & 389 & 23.3 \\
- No & & 76.7 \\
Endometriosis & 54 & \\
- Yes & 453 & 10.7 \\
- No & & 89.3 \\
\hline
\end{tabular}

Table 4. Association between endometriosis and infertility among participants $(n=507)$.

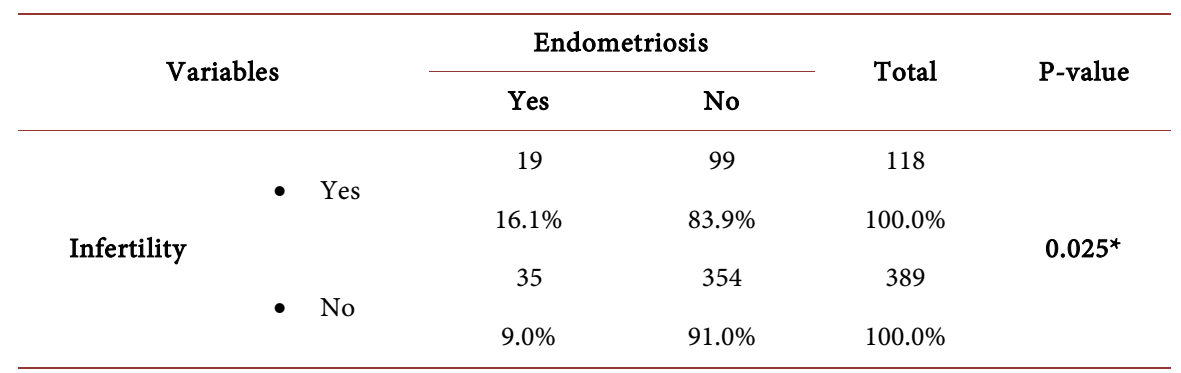

${ }^{\star}$ Fisher's Exact Test was used.

\section{Discussion}

Endometriosis is defined as the presence of endometrial tissue outside the uterus2. It is responsible for varied and disabling symptoms and also has adverse effects on reproductive potential. Signs and symptoms arise from cyclic bleeding into the surrounding tissues resulting in inflammation and formation of scarring and adhesions [1]. Women with endometriosis typically have a range of pelvic-abdominal pain symptoms, including dysmenorrhea, dyspareunia, heavy menstrual bleeding, non-menstrual pelvic pain, pain at ovulation, dysphasia, and dysuria, as well as chronic fatigue [12]. The associated symptoms can impact the patient's general physical, mental, and social well-being [13]. This is a crosssectional study was conducted among 507 of the studied women, Jeddah, KSA. The study aimed to.

The prevalence of endometriosis is underestimated because of the need for laparoscopy, which is considered the gold standard, to confirm the diagnosis. At least $10 \%$ of all women in reproductive age are affected by the disease [14]. In accordance with this, our study found that $10.7 \%$ of cases had endometriosis. In contrast to our results another a retrospective study conducted among 372 cases which demonstrates a very high incidence of endometriosis 48.33\% [15]. Another study was carried out 200 patients who presented with symptoms of dysmenorrhea, dyspareunia, chronic pelvic pain with or/without infertility were studied in the women of reproductive age group which found that $25 \%$ (50 cases) were diagnosed as cases of endometriosis [16]. In Egypt, another study conducted among 100 patients attending Menoufia University Hospital and sub- 
jected to diagnostic laparoscopy reported that $33 \%$ of them had endometriosis [17]. Another study conducted among 1285 women reported; the estimated point prevalence of endometriosis was $4.0 \%$ [18].

The true incidence of endometriosis is difficult to establish since endoscopy or laparotomy is required for a definitive diagnosis and the disease may still undoubtedly exist in patients who are asymptomatic.

Epidemiological studies estimated the infertility prevalence in reproductive age between 5\% - 30\% worldwide [19]. According to prevalence of infertility, we found that $23.3 \%$ of women were diagnosed with primary or secondary infertility. Similar to our results, another study reported the prevalence of infertility was $22.5 \%$ [16]. A meta-analysis study in Iran was conducted on 13 Iranian studies during 2003-2011 which reported the overall infertility prevalence 13.2\% [20]. In a study on all couples in Canada-2011, the prevalence of infertility was $11.5 \%$ $15.7 \%$ [21].

Classic studies have suggested that $25 \%$ to $50 \%$ of infertile women have endometriosis and $30 \%-50 \%$ of women with endometriosis are infertile [22]. Regarding association between endometriosis and infertility among participants, our study reported that only $16.1 \%$ of cases with endometriosis had infertility but the association was not significant $(\mathrm{p}=0.025)$. In contrast to our results, another study found that endometriosis was the cause of infertility $73.3 \%$ of cases [16]. Another study found that significant associations were observed between endometriosis and fertility problems [18]. The exact mechanism by which endometriosis causes infertility is still unclear. The projected sequences of the causes of infertility in cases of endometriosis are by an altered peritoneal fluid composition as a result of hormonal, genetic and environmental factors [23] [24].

\section{Conclusion}

Endometriosis is a common disorder with a variety of causes and symptoms. Although many women with endometriosis get pregnant and deliver healthy infants, endometriosis is highly associated with infertility among women. More studies are needed to investigate the pathobiology of this condition.

\section{Conflicts of Interest}

The author declares no conflicts of interest regarding the publication of this paper.

\section{References}

[1] Azizad-Pinto, P. and Clarke, D. (2014) Thoracic Endometriosis Syndrome: Case Report and Review of the Literature. Permanente Journal, 18, 61-65. https://doi.org/10.7812/TPP/13-154

[2] Cramer, D.W. and Missmer, S.A. (2002) The Epidemiology of Endometriosis. Annals of the New York Academy of Sciences, 955, 11-22. (Discussion 34-6, 396-406) https://doi.org/10.1111/j.1749-6632.2002.tb02761.x 
[3] Nnoaham, K.E., Hummelshoj, L., Webster, P., d'Hooghe, T., de Cicco Nardone, F., de Cicco Nardone, C., et al. (2011) Impact of Endometriosis on Quality of Life and Work Productivity: A Multicenter Study across Ten Countries. Fertility and Sterility, 96, 366-373e8. https://doi.org/10.1016/j.fertnstert.2011.05.090

[4] World Health Organization (2009) Revised Glossary on Assisted Reproductive Terminology (ART). Fertility and Sterility, 92, 1520-1524.

https://doi.org/10.1016/j.fertnstert.2009.09.009

[5] World Health Organization (2010) WHO Laboratory Manual for the Examination and Processing of Human Semen.

[6] Hodin, S. (2017) The Burden of Infertility: Global Prevalence and Women's Voices from around the World.

[7] Mavrelos, D. and Saridogan, E. (2015) Treatment of Endometriosis in Women Desiring Fertility. The Journal of Obstetrics and Gynecology of India, 65, 11-16. https://doi.org/10.1007/s13224-014-0652-y

[8] Hughes, E.G., Fedorkow, D.M. and Cllins, J.A. (1993) A Quantitative Overview of Controlled Trials in Endometriosis-Associated Infertility. Fertility and Sterility, 59, 963-970. https://doi.org/10.1016/S0015-0282(16)55911-1

[9] Schwartz, D. and Mayaux, M.J. (1982) Female Fecundity as a Function of Age: Results of Artificial Insemination in 2193 Nulliparous Women with Azoospermic Husbands. CECOS. The New England Journal of Medicine, 306, 404-406. https://doi.org/10.1056/NEJM198202183060706

[10] Collins, J.A., Burrows, E.A. and Wilan, A.R. (1995) The Prognosis for Live Birth among Untreated Infertile Couples. Fertility and Sterility, 64, 22-28. https://doi.org/10.1016/S0015-0282(16)57650-X

[11] Teng, S.W., Horng, H.C., Ho, C.H., Yen, M.S., Chao, H.T., Wang, P.H., Chang, Y.H., Chang, Y., Chao, K.C., Chen, Y.J. and Chuang, C.M. (2016) Women with Endometriosis Have Higher Comorbidities: Analysis of Domestic Data in Taiwan. Journal of the Chinese Medical Association, 79, 577-582. https://doi.org/10.1016/j.jcma.2016.04.006

[12] Giudice, L.C. and Kao, L.C. (2004) Endometriosis. The Lancet, 364, 1789-1799. https://doi.org/10.1016/S0140-6736(04)17403-5

[13] Nnoaham, K.E., Hummelshoj, L., Kennedy, S.H., Jenkinson, C. and Zondervan, K.T. (2012) World Endometriosis Research Foundation Women Health Symptom Survey. Developing Symptom-Based Predictive Models of Endometriosis as a Clinical Screening Tool: Results from a Multicenter Study. Fertility and Sterility, 98, 692-701. https://doi.org/10.1016/j.fertnstert.2012.04.022

[14] Kennedy, S., Bergqvist, A., Chapron, C., D’Hooghe, T., Dunselman, G., Saridogan, E., et al. (2005) ESHRE Guideline on the Diagnosis and Management of Endometriosis. Human Reproduction, 20, 2698-2704. https://doi.org/10.1093/humrep/dei135

[15] Mao, A.J. and Anastasi, J.K. (2010) Diagnosis and Management of Endometriosis: The Role of the Advanced Practice Nurse in Primary Care. Journal of the American Association of Nurse Practitioners, 22, 109-116. https://doi.org/10.1111/j.1745-7599.2009.00475.x

[16] Mishra, V.V., Gaddagi, R.A., Aggarwal, R., Choudhary, S., Sharma, U. and Patel, U. (2015) Prevalence; Characteristics and Management of Endometriosis amongst Infertile Women: A One Year Retrospective Study. Journal of Clinical and Diagnostic Research, 9, QC01-QC03. https://doi.org/10.7860/JCDR/2015/13687.6125

[17] Valson, H., Kulkarni, C. and Teli, B. (2016) Study of Endometriosis in Women of 
Reproductive Age, Laparoscopic Management and Its Outcome. International Journal of Reproduction, Contraception, Obstetrics and Gynecology, 5, 514-519. https://doi.org/10.18203/2320-1770.ijrcog20160401

[18] Gad, M.S., Abdel-Gayed, A.M., Dawoud, R.M. and Amer, A.F. (2017) Prevalence of Endometriosis in Unexplained Infertility and Chronic Pelvic Pain in Women Attending Menoufia University Hospital. Menoufia Medical Journal, 30, 356-360. https://doi.org/10.4103/mmj.mmj_415_16

[19] Flores, I., Abreu, S., Abac, S., Fourquet, J., Laboy, J. and Ríos-Bedoya, C. (2008) Self-Reported Prevalence of Endometriosis and Its Symptoms among Puerto Rican Women. International Journal of Gynecology \& Obstetrics, 100, 257-261. https://doi.org/10.1016/j.ijgo.2007.08.010

[20] Bentley, G.R. and Mascie-Taylor, C.N. (2000) Infertility in the Modern World: Present and Future Prospects. Cambridge University Press, Cambridge, UK. https://doi.org/10.1017/CBO9780511613036

[21] Moghadam, A.D., Delpisheh, A. and Sayehmiri, K. (2014) The Trend of Infertility in Iran, an Original Review and Meta-Analysis. Nursing Practice Today, 1, 46-52.

[22] Bushnik, T., Cook, J.L., Yuzpe, A.A., Tough, S. and Collins, J. (2012) Estimating the Prevalence of Infertility in Canada. Human Reproduction, 27, 738-746. https://doi.org/10.1093/humrep/der465

[23] Missmer, S.A., Hankinson, S.E., Spiegelman, D., Barbieri, R.L., Marshall, L.M. and Hunter, D.J. (2004) Incidence of Laparoscopically Confirmed Endometriosis by Demographic, Anthropometric, and Lifestyle Factors. American Journal of Epidemiology, 160, 784-796. https://doi.org/10.1093/aje/kwh275

[24] Gilabert-Estelles, J., Ramon, L.A., España, F., Gilabert, J., Castello, R. and Estelles, A. (2006) Expression of Fibrinolytic Components in Endometriosis. Pathophysiology of Haemostasis and Thrombosis, 35, 136-140. https://doi.org/10.1159/000093556 